\title{
EFL Students in English-Medium and EAP Courses in Turkey*
}

\section{Meltem Huri Baturay ${ }^{1}$, Ahmet Erdost Yastibas ${ }^{2}$}

${ }^{1}$ Atılım University, Ankara,Turkey.e-mail:meltem.baturay@atilim.edu.tr

${ }_{2}^{2}$ Gazi University, Ankara, Turkey.e-mail:ahmeterdost@gmail.com

\begin{tabular}{|c|c|}
\hline ARTICLE INFO & ABSTRACT \\
\hline $\begin{array}{l}\text { Keywords: } \\
\text { English-medium } \\
\text { instruction, English for } \\
\text { academic purposes, EFL } \\
\text { students, English- } \\
\text { medium courses, EAP } \\
\text { courses }\end{array}$ & $\begin{array}{l}\text { The present study aimed to determine university students' perceptions } \\
\text { regarding EM and EAP courses and how they studied EM and EAP courses and } \\
\text { their exams. It was designed as a qualitative study. Eight students } \\
\text { participated in the study. The data were collected through semi-structured } \\
\text { interviews and analysed by content analysis method. The findings of the } \\
\text { study indicated that the students who perform well in EM and EAP courses } \\
\text { and who perform well in EM courses but have difficulty in EAP courses are } \\
\text { motivated to receive EM courses and have positive attitudes toward EM } \\
\text { courses. Yet, the students who perform well in EM and EAP courses are more } \\
\text { motivated to receive EAP courses and have more positive attitudes toward } \\
\text { EAP courses. The findings also indicated that the ways the students study EM } \\
\text { and EAP courses and for their exams have both similarities and differences. } \\
\text { The findings were discussed. The pedagogical implications and limitations of } \\
\text { the study were explained, and suggestions for further research were made. }\end{array}$ \\
\hline
\end{tabular}

DOI:

http://dx.doi.org/10.21093

/ijeltal.v6i1.883

How to cite:

Baturay, M.H. \& Yastibas, A.E. (2021). EFL Students in English-Medium and EAP Courses in Turkey. Indonesian Journal of English Language Teaching and Applied Linguistics, 6(1), 89-101

* Preliminary findings of the present study were presented as an oral presentation at the $2^{\text {nd }}$ ILTERG Conference on 16-17 October 2020

\section{Introduction}

English is considered the language of science, commerce, and communication, so it is commonly used to instruct in courses in the world. Similarly, it is the most commonly used foreign language to teach courses in Turkey because many Turkish universities have faculties or departments such as faculty of engineering and faculty of medicine which offer English medium (EM) courses. Therefore, EM courses have an important place in the Turkish higher education system. 
EM courses require students to use English for academic purposes (EAP) because the contents of EM courses are delivered in English, students are assessed and evaluated in English, and all instructional activities are done in English. Therefore, students are supposed to use English for academic purposes well to benefit from EM courses. This situation shows that EM courses and EAP are closely connected with each other. Yet, one of the researchers who taught EAP courses in an EM faculty noticed that there were two groups of students in his classes. The students in the first group did not have any difficulty in the EAP courses and reported that they also did not have any difficulty in their EM courses. Yet, the students in the second group had difficulty in EAP courses, while they mentioned that they did not have any difficulty in their EM courses. In this case, difficulty means that students had problems such as showing low performance in the exams in the course.

As English medium instruction is the use of English to teach academic courses at universities, as EM courses have been studied under the name of English medium instruction in the literature, and as the main focus of the present study is on EM courses, English medium instruction was replaced with EM courses in the literature review. When the literature was reviewed to understand what may cause this situation, it was seen that several studies were conducted on EM courses with students (Dafouz \& Camacho-Miñano, 2016; Du \& Jackson, 2018; Goodman, 2019; Hengsadeekul et al., 2014; Huang, 2015; Mengxia Kong \& Wei, 2019; Macaro \& Akincioğlu, 2017; Margic \& Vodopija-Krstanovic, 2018; Pritasari et al., 2019; RiveroMenéndez et al., 2018; Suliman \& Tadros, 2011; Wanphet \& Tantawy, 2018; Wang et al., 2018), with lecturers (Başıbek et al., 2014; Tuomainen, 2018), and with students and lecturers (Al-Kahtany et al., 2016; Barrios et al., 2016; Querol-Julián \& Camiciottoli, 2019; Tatzl, 2011; Thomas, 2019; Yang et al., 2019; Zhang, 2017). Some of these studies have found out that a low level of English proficiency is a problem in EM courses for students (Al-Kahtany et al., 2016; Başıbek et al., 2014; Goodman, 2019; Huang, 2015; Pritasari et al., 2019; Suliman \& Tadros, 2011; Wang et al., 2018), for lecturers (Tuomainen, 2018), and for both of them (Barrios et al., 2016; Querol-Julián \& Camiciottoli, 2019; Tatzl, 2011; Thomas, 2019) because English language proficiency is a requirement for effective EM courses (Thomas, 2019). Due to the low levels of English proficiency, students have been reported to encounter issues (Wanphet \& Tantawy, 2018) such as not understanding the course content and their lecturers' instructions (Wang et al., 2018), understanding vocabulary, terminology, and exam questions (Tatzl, 2011), and engaging in classroom debates and group work (Wang et al., 2018). This increases students' study burden (Wang et al., 2018). That is, they may have to study more outside the classroom (Yang et al., 2019). To deal with such issues, students may utilize different ways such as using their mother tongues (Wanphet \& Tantawy, 2018; Wang et al., 2018; Yang et al., 2019) and peer support (Wang et al., 2018).

Second language motivation is an important part of second language achievement and affects EM courses (Du \& Jackson, 2018). Therefore, motivation has been focused on in some studies which have indicated that students are motivated for EM courses (Du \& Jackson, 2018; Huang, 2015). Hengsadeekul et al. (2014) revealed that instrumental goals are effective in students' motivational orientation and preferences for EM courses. The reasons why students want to receive EM courses support this finding. For example, students expect EM courses to improve their level of English proficiency (Barrios et al., 2016; Huang, 2015; Macaro \& Akincioglu, 2017; Wanphet \& Tantawy, 2018; Zhang, 2017) and to strengthen their professional knowledge (Huang, 2015). Therefore, students can consider EM courses useful 
and helpful (Huang, 2015). Considering the instrumental goals of students, they have been found out to have positive attitudes towards EM courses (Mengxia Kong \& Wei, 2019; Macaro \& Akincioglu, 2017) and favor them (Mengxia Kong \& Wei, 2019; Tatzl, 2011) though AlKahtany et al. (2016) indicated that students do not favor EM courses, while their lecturers favor them.

Students have reported that EM courses have improved their English (Tatzl, 2011) and that EM courses have affected their academic performance negatively due to their low level of English proficiency (Al-Kahtany et al., 2016; Goodman, 2019) though Dafouz \& CamachoMiñano (2016) indicated that EM courses do not lower students' academic achievement. Regarding the effects of EM courses on students, students have been found out to use some strategies to deal with EM courses. According to Rivero-Menéndez et al. (2018), they can set organizational goals more effectively, have effective time-management skills, and are aware that they have to do extra work in EM courses. In addition, Suliman \& Tadros (2011) revealed that students could use positive reappraisal, self-controlling, social support, and planfulproblem solving strategies in dealing with EM courses.

As seen, no study focuses on the research problem mentioned above in the literature. Therefore, the present study aimed to find out the opinions of EFL students about EM courses and EAP and the ways they study EM and EAP courses, and they study for the exams of EM and EAP courses through the following research questions:

1. What do the students who perform well in EM and EAP courses think about EM and EAP courses?

2. What do the students who perform well in EM courses but have difficulty in EAP courses think about EM and EAP courses?

3. How do the students who perform well in EM and EAP courses study EM and EAP courses?

4. How do the students who perform well in EM courses but have difficulty in EAP courses study EM and EAP courses?

5. How do the students who perform well in EM and EAP courses study for the exams of EM and EAP courses?

6. How do the students who perform well in EM courses but have difficulty in EAP courses study for the exams of EM and EAP courses?

\section{Research Methodology}

\subsection{Research Design}

A case study is a kind of qualitative research (Creswell \& Poth, 2018) which researches a case or cases within its/their real context(s) (Yin, 2009). Accordingly, the present study aimed to study the case - that is, why some EAP students perform well in both EM and EAP courses and why some EAP students perform well in EM courses but have difficulty in EAP courses in the case's real context; therefore, the present study was designed as a qualitative case study.

\subsection{Participants}

Purposeful sampling including criterion sampling allowed the researchers to make their sampling line up with the purpose of the study (Creswell, 2007). Accordingly, eight female EAP students who were the second-grade students in an EM department of a Turkish 
university and whose ages were between 19 and 23 were chosen to participate in the research according to the following criteria:

1. Performing well in both EM and EAP courses, and

2. Performing well in EM courses, but having difficulty in EAP courses.

Four of these participants reported that they performed well in both EM and EAP courses, while four of them mentioned that they performed well in EM courses but had difficulties in EAP courses given.

\subsection{Data Collection Tool}

A semi-structured written interview was prepared in accordance with the research questions of the present study. There were five questions relating to each research question. These questions are:

1. What do you think about the EM and EAP courses given in your department?

2. How do you study the EM courses given in your department?

3. How do you study for the exams of the EM courses given in your department?

4. How do you study the EAP courses given in your department?

5. How do you study for the exams of the EAP courses given in your department?

\subsection{Data Analysis}

The collected data were content analyzed by the researchers depending on the framework suggested by Yıldırım \& Şimşek (2013). The written responses of the participants to the questions were read many times by the researchers, and the codes were derived from the data. The generated data were presented and organized according to the derived codes without any comment. The researchers interpreted the data without any conflict with the description of the data.

\subsection{Trustworthiness of the Present Study}

The researchers first content-analyzed the data separately. After they completed their analyses, they came together, compared their analyses, focused on the differences between them, and made changes in the content analysis of the data if necessary by reaching a consensus on each change made. As Lincoln \& Guba (1985) suggested, this technique was used to provide the trustworthiness of the present study.

\section{Findings}

The findings were presented according to the research questions in order. It is necessary to know that departmental courses refer to EM courses, while academic English courses refer to EAP courses in the excerpts to understand the findings part better.

\subsection{Opinions of the Students Who Performed Well in EM and EAP Courses about EM and EAP Courses}

Two of the students who performed well in EM and EAP courses considered both courses as useful and necessary, as understood from the excerpts below.

Student 1: "I think that departmental courses in English and academic English courses are very useful for us."

Student 4: "I believe that courses are necessary." 
In addition, two of these students believed that both courses improved each other. The excerpts below support this.

Student 1: "I think that especially receiving departmental courses in English improves my academic English."

Student 2: "I can plan how I should write when we write a long paper in our department more comfortably thanks to the essay we have written in academic English courses."

One of the students also had positive attitudes toward English due to her level of English proficiency as the excerpt below indicates:

Student 3: "I have positive feelings about English. I think that I have a good level of English proficiency and I do not have any problem in the courses."

\subsection{Opinions of the Students Who Performed Well in EM Courses but Had Difficulty in EAP Courses about EM and EAP Courses}

Two of the students who performed well in EM courses but had difficulty in EAP courses considered EAP courses as difficult to understand and EM courses as understandable. To illustrate:

Student 6: "Departmental courses are more understandable and informative. Yet, academic English courses are complicated and more difficult to understand."

Student 7: "Departmental courses are given more simply and slowly so that they are understandable for me, but academic English courses are sometimes given faster, there are a lot of unknown words, and instructors have different accents, so I have difficulty in academic English courses."

One of these students found EAP courses not useful, but EM courses useful. The excerpt below indicates this.

Student 5: "I do not think that academic English courses are useful because they do not help me improve my proficiency. It is not the same for departmental courses because we know how to study them."

The last student who performed well in EM courses but had difficulty in EAP courses considered EAP courses more challenging and strict, but EM courses more clear. The excerpt below supports this.

Student 8: "English in departmental courses is used more clearly. Yet, academic English courses are very strict and challenging students."

\subsection{Ways of Studying EM and EAP Courses of the Students Who Performed Well in EM and EAP Courses}

It is necessary to know that students reported more than one way to study EM and EAP courses in this part. Two of the students who performed well in EM and EAP courses studied EM courses by learning the meanings of unknown words in EM coursebooks. The excerpts below demonstrate this.

Student 1: "... translating the unknown words to Turkish." 
Student 2: "I write the words that I do not understand. Learning the meanings of the words in the topic to be studied in class before the lessons and reading what is studied in the lesson are very beneficial."

Two of these students read their coursebooks to study EM courses, as indicated by the excerpts below.

Student 2: "Learning the meanings of the words in the topic to be studied in class before the lessons and reading what is studied in the lesson are very beneficial."

Student 4: "I read the books related to the courses."

Also, two students of these students took notes to study EM courses, as understood from the excerpts below.

Student 2: "I continuously note down what I consider important in the lessons."

Student 3: "I study by ... taking notes in the class and reviewing notes at home."

Student 1 also reported that she studied EM courses "by highlighting important parts for me with colorful pencils...," and student 3 said that she studied "by carefully listening to the lessons."

In addition to the ways of studying EM courses, one of these students reported that she did not study EAP courses, while another student stated that she did "the activities on the coursebook." To study EAP courses, student 1 used translation and focused on one part of the content of EAP courses as she said:

"By translating unknown words to Turkish. I try to understand the structure and contents of essays."

Student 2 used active participation and reviewing course materials before the lessons started as she stated:

"I try to participate in the lesson actively. Reading the articles in the coursebook before the lessons is very useful because it becomes easy to discuss the topic and answer questions as I think about the questions related to the articles."

\subsection{Ways of Studying EM and EAP Courses of the Students Who Performed Well in EM Courses but Had Difficulty in EAP Courses}

It is necessary to know that students reported more than one way to study EM and EAP courses in this part. Two of the students who performed well in EM courses but had difficulties in EAP courses relied on their mother tongue (Turkish) to study EM. To illustrate:

Student 6: "I first study the topics of EM courses in Turkish and then in English. I can remember them more easily."

Student 8: "I first translate the topics to Turkish and then study them in English."

Student 5 mentioned that she studied "systematically and regularly," while student 7 preferred studying notes to study EM as she stated: "I write or study the notes I take on the internet or in the class." Student 6 also added that she studied EM courses by reading "the slides of course lecturers and coursebooks."

Besides the ways of studying EM courses, two of these students preferred learning the unknown words to study EAP course. The excerpts below show this. 
Student 5: "I ... learn the meanings of the words I do not know."

Student 6: "I try to learn the meanings of unknown words in the coursebook..."

In addition to these ways, student 5 stated that she also "read the texts in the coursebook," and student 6 said she practiced "writing."

Another student studied EAP courses by doing "the online and assigned activities in the coursebooks." The last student who performed well in EM courses but had difficulties in EAP courses studied EAP courses preferred studying EAP courses by peer support, as shown in the excerpt below.

Student 8: "I study with my friends."

\subsection{Ways of Studying for the Exams of EM and EAP Courses of the Students Who Performed Well in EM and EAP Courses}

It is significant to know that students reported more than one way to study for the exams of EM and EAP courses in this part. Two of the students who performed well in EM and EAP courses used notes when they studied for the exams of EM courses. The excerpts below indicate this.

Student 3: "I rewrite and review notes in the exam period."

Student 4: "I take notes from the slides."

Two of these students mentioned that they studied EM courses regularly to study for the exams of EM courses, as showed by the excerpts.

Student 1: "By not studying on the last days before the exams, but studying after the classes regularly."

Student 4: "I read the coursebooks regularly."

Student 2 studied for the exams of EM courses by studying the meanings of unknown words and taking notes about what she considered important and did not understand well as she stated:

"I first learn the meanings of unknown words. I study by reading and writing the parts that have been studied in the lessons, that I consider important, or that I find difficult to understand. I watch videos about the parts which I have not understood in the lessons."

In addition to the ways of studying for the exams of EM courses, three of these students focused on learning the meanings of the words when they studied for the exams of EAP courses. The excerpts below clearly support this.

Student 2: "I try to memorize the words when I study for the exams."

Student 3: "I review the words we have learned in the class before the exams."

Student 4: "I learn the meanings of unknown words."

While student 4 also preferred doing "the exercises on the coursebooks," students 1 and 2 also preferred reviewing the content studied in the lesson to study for the exams of EAP courses. The excerpts below indicate this.

Student 1: "I review everything studied before the exams." 
Student 2: "I review what has been taught in the lesson. I study the parts which I have not understood well in the class more."

\subsection{Ways of Studying for the Exams of EAP Courses of the Students Who Performed Well in EM Courses but Had Difficulty in EAP Courses}

It is significant to know that students reported more than one way to study for the exams of EM and EAP courses in this part. One of the students who performed well in EM courses but had difficulties in EAP courses study stated that he studied "on the last days before the exams," while another student who performed well in EM courses but had difficulties in EAP courses study explained that she studied "regularly and systematically." Student 6 relied on her mother tongue (Turkish) when she studied for the exams of EM courses, as understood from the excerpt.

Student 6: "I first study the topics of EM courses in Turkish and then in English. I can remember them more easily. Besides, I read the slides of course lecturers and coursebooks."

As seen, she also focused on the slides of her course lecturers in studying for the exams. Student 7 used note-taking in studying for the exams of EM courses, as seen in the excerpt below.

Student 7: "I study the notes from voice recordings and taken in the class. I take notes of the important parts from slides and coursebooks. My friend and I tell the topics to each other in Turkish."

In addition to note-taking, she also used peer support and her mother tongue (Turkish) in studying for the exams of EM courses.

Besides the ways of studying for the exams of EM courses, student 5 who performed well in EM courses but had difficulties in EAP courses stated that she did not "know how to study," while student 8 who performed well in EM courses but had difficulties in EAP courses mentioned that she studied her "friends' notes" to study for the exams of EAP courses. Students 6 and 7 preferred studying vocabulary when they studied for the exams of EAP courses as the excerpts show.

Student 6: "I try to learn the meanings of unknown words in the coursebook and practice writing."

Student 7: "I focus on vocabulary more and do online activities."

In addition to vocabulary, student 6 concentrated on writing, and student 7 focused on doing online activities.

\section{Discussion}

One of the findings of the study is that all of the students who perform well in EM and EAP courses and the ones who perform well in EM courses but have difficulty in EAP courses have positive opinions about EM courses, which is consistent with the literature (Du \& Jackson, 2018; Huang, 2015; Macaro \& Akincioglu, 2017; Mengxia Kong \& Wei, 2019; Tatzl, 2011). The students who perform well in EM and EAP courses consider both of these courses as useful and necessary, believed that both of the courses helped them to improve themselves in both courses, and had positive attitudes toward both of the courses. This clearly shows that such 
students are highly motivated to receive, favor, and have positive attitudes toward EM and EAP courses, which is similar to the findings of Macaro \& Akincioglu (2017) and Mengxia Kong \& Wei (2019) who indicated that students have positive attitudes towards English medium instruction (EMI) and of Mengxia Kong \& Wei (2019) and Tatzl (2011) who found out that students favor EMI. Consistent with what Macaro \& Akincioglu (2017), Mengxia Kong \& Wei (2019), and Tatzl (2011) stated about EM courses, the students who perform well in EM courses but have difficulty in EAP courses are more motivated to receive EM courses, and they favor such courses more. It is because they find EM courses more understandable and clear than EAP courses. According to these students, EAP courses are challenging and difficult to understand. This finding may be partly explained by the students' level of English proficiency. According to Thomas (2019), English language proficiency is a requirement for effective EMI, but the level of English proficiency can be a problem in EM courses for students (Al-Kahtany et al., 2016; Barrios et al., 2016; Başıbek et al., 2014; Goodman, 2019; Huang, 2015; Pritasari et al., 2019; Querol-Julián \& Camiciottoli, 2019; Suliman \& Tadros, 2011; Tatzl, 2011; Thomas, 2019; Wang et al., 2018). Similarly, according to the last finding of the study mentioned, the students who perform well in EM courses but have difficulty in EAP courses seem to have a low level of English proficiency, which may cause them to experience difficulties in EAP courses. This situation makes this finding interesting because according to the literature, when students have a low level of English proficiency, they can be also expected to encounter difficulties in EM courses (Al-Kahtany et al., 2016; Barrios et al., 2016; Başıbek et al., 2014; Goodman, 2019; Huang, 2015; Pritasari et al., 2019; Querol-Julián \& Camiciottoli, 2019; Suliman \& Tadros, 2011; Tatzl, 2011; Thomas, 2019; Wang et al., 2018). Yet, according to the students who perform well in EM courses but have difficulty in EAP courses, they do not encounter any issues in EM courses. A possible explanation for this interesting finding may be that they may deal with the effects of their low level of English proficiency on EM courses through different ways of studying EM courses. According to the present study, these students tend to use translation from English to Turkish in EM courses and spend more time on studying EM courses. Spending more time on EM courses is consistent with Yang et al. (2019) and Wang et al. (2017) who mentioned that EM courses increase students' study burden. Hengsadeekul et al. (2014) found out that instrumental goals are effective in students' motivational orientation and preferences for EM courses. Accordingly, the instrumental goal of the students who perform well in EM course, but have difficulties in EAP is graduating from the university with a degree in their majors so that they can work in the future. The only way to achieve this aim is to be successful in EM courses. Therefore, unlike the students who perform well in EM and EAP courses, these students may not consider EAP courses as an important part of this goal, so they may favor

Another interesting finding of the present study is that unlike the students who perform well in EM and EAP courses, the students who perform well in EM courses but have difficulties in EAP courses do not favor EAP courses, and they have negative attitudes toward EAP courses. This finding is interesting because students use English for academic purposes when they receive their departmental courses in English. Therefore, there is a close relationship between EM courses and EAP. A possible explanation for this finding may be that the students who perform well in EM and EAP courses are more aware of the close relationship between EM courses and EAP as they know that both EM and EAP courses help them to improve their EM and EAP skills. They may also know that EM courses improve their level of English proficiency as stated in the literature (Barrios et al., 2016; Huang, 2015; Macaro \& 
Akincioglu, 2017; Wanphet \& Tantawy, 2018; Zhang, 2017), and so does EAP. Therefore, this awareness can cause them to be more motivated in both EM and EAP courses than the ones who perform well in EM courses but have difficulty in EAP courses.

Another finding of the present study is that the students who perform well in EM and EAP courses prefer taking notes, reading the EM coursebooks, and learning the meanings of unknown words when they study EM course unlike Wanphet \& Tantawy (2018), Wang et al. (2018) and Yang et al. (2019) who found out that students in EM courses rely on their mother tongues in studying EM courses. Yet, this finding of the literature is consistent with the finding of the present study that the students who perform well in EM courses but have difficulty in EAP courses study EM course by using their mother tongues in addition to taking notes, reading EM coursebooks, and being systematic and regular. This finding might be explained by the fact that the students who perform well in EM courses but have difficulty in EAP courses may have lower levels of English proficiency than the English proficiency levels of the ones who perform well in EM and EAP courses.

The findings of the present study have shown that the students who perform well in EM and EAP courses study EAP courses by doing the activities in the coursebooks, learning the meanings of unknown words, participation, and reviewing the course content before lessons, while the ones who perform well in EM courses but have difficulty in EAP courses use learning the meanings of unknown words, reading the texts in the coursebooks, practicing writing, and doing the online activities and the activities in the coursebook. This is consistent with Rivero-Menéndez et al. (2018) and Suliman \& Tadros (2011) who stated that students use different strategies and/or ways to deal with EMI. Both groups of students use similar strategies such as doing the activities in the coursebook, reviewing the course content (such as reading texts) before the lessons, and learning the meanings of unknown words. These ways seem to work well with the students who perform well in EM and EAP courses, but not with the ones who perform well in EM courses but have difficulties in EAP courses. There may be two possible reasons for this finding. The first one is motivation. According to Du \& Jackson (2018), motivation in the second language is an important part of achievement in the second language. Similarly, the findings of the present study previously explained indicate that the students who perform well in EM courses but have difficulty in EAP courses are less motivated in EAP courses, so this may affect their achievement in EAP courses negatively. The second possible reason is the level of English proficiency. The level of English proficiency affects the efficiency of EM courses (Al-Kahtany et al., 2016; Barrios et al., 2016; Başıbek et al., 2014; Goodman, 2019; Huang, 2015; Pritasari et al., 2019; Querol-Julián \& Camiciottoli, 2019; Suliman \& Tadros, 2011; Tatzl, 2011; Thomas, 2019; Wang et al., 2018). Similarly, it can affect the efficiency of EAP courses. Therefore, even if both groups of students in the present study use similar strategies in studying EAP courses, the ways of studying EAP courses can work better with the students who have higher levels of English proficiency, that is, the ones who perform well in EM and EAP courses. Asking for peer support which is one of the ways used by one of the students who have difficulties in EAP courses is also an indicator of lower levels of English proficiency. These two reasons can also help to understand why the students who perform well in EM courses but have difficulties in EAP courses consider EAP courses as difficult to understand.

According to the findings of the present study, both of the students who perform well in EM and EAP courses and who perform well in EM courses but have difficulties in EAP courses use 
different ways to study for the exams of EM courses, which is in line with Rivero-Menéndez et al. (2018) and Suliman \& Tadros (2011) who stated that students use different strategies and/or ways to deal with EMI. The findings of the present study have shown that the students who perform well in EM and EAP courses take notes, study regularly, and learn the meanings of the unknown words when they study for the exams of EM courses, while each of the students who perform well in EM courses but have difficulties in EAP courses prefers different ways of studying for the exams of EM courses including studying regularly, taking notes, studying on the last days before the exam, peer support, and using their mother tongue. The use of peer support (Wang et al., 2018) and mother tongue (Wanphet \& Tantawy, 2018; Wang et al., 2018; Yang et al., 2019) to study for the exams of EM are two of the strategies that students in EM courses have been reported to use in studying EM courses. The use of these two ways to study may address the lower levels of English proficiency in the students who perform well in EM courses but have difficulties in EAP courses.

The last finding of the present study is that the students who perform well in EM and EAP courses learn the meanings of unknown words, do the exercises in the coursebooks, and reviewing what has been studied in the exam when they study for the exams of EAP courses. The ones who perform well in EM courses but have difficulty in EAP courses study vocabulary, others' lesson notes, and do online activities to study for the exams of EAP courses. That the ways the students use to study work well with them or not may depend on their levels of English proficiency and their attitudes toward EM and EAP courses. That is, the students who perform well in EM courses but have difficulties in EAP courses seem to have lower levels of English proficiency and negative opinions about EAP courses. Therefore, the ways they use to study for the exams of EAP courses may not work as well as the ways the ones who have higher levels of English proficiency and more positive opinions about EAP courses.

\section{Conclusion}

The present study indicated that the students who perform well in EM and EAP courses and who perform well in EM courses but have difficulty in EAP courses are motivated to receive EM courses and have positive attitudes toward EM courses. Yet, the students who perform well in EM and EAP courses are more motivated to receive EAP courses and have more positive attitudes toward EAP courses. The ways both groups of students study EM and EAP courses show both similarities and differences, so do the ways both groups of students study for the exams of EM and EAP courses.

\subsection{Pedagogical Implications of the Study}

The present study has two pedagogical implications. The first one is that the connection between EM courses and EAP should be clearly explained to students because students may not realize or know that EAP is an important part of EM courses as they use English for academic purposes in EMI. Therefore, their opinions about EAP courses can become more positive, which may result in an increase in their motivation to receive EAP courses.

The second pedagogical implication of the study is that the English proficiency levels of students may not be sufficient enough to understand EM and EAP courses. Therefore, providing extra English language training can help such students overcome the weaknesses resulting from their lower levels of English proficiency. With such training, they can 
understand the contents of EM and EAP courses better and perform better in both EM and EAP courses.

\subsection{Limitations of the Study and Suggestions for Further Studies}

The present qualitative study was conducted with eight participants in Turkey. Therefore, its findings can not be generalized for other research contexts. Yet, similar studies can be implemented with the same research method or other research methods and with more participants so that a better understanding of the issue under investigation in the present study can be better understood, and better solutions can be provided to students to improve themselves in EM courses and EAP.

\section{References}

Al-Kahtany, A. H., Faruk, S. M. G., \& Al Zumor, A. W. Q. (2016). English as the medium of instruction in Saudi higher education: Necessity or hegemony? Journal of Language Teaching and Research, 7(1), 49-58. http://dx.doi.org/10.17507/jltr.0701.06

Barrios, E., López-Gutiérrez, A., \& Lechuga, C. (2016). Facing challenges in English Medium Instruction through engaging in an innovation project. Procedia - Social and Behavioral Sciences, 228, 209-214.

Başıbek, N., Dolmacl, M., Cengiz, B. C., Bür, B., Dilek, Y., \& Kara, B. (2014). Lecturers' perceptions of English medium instruction at engineering departments of higher education: A study on partial English medium instruction at some state universities in Turkey. Procedia - Social and Behavioral Sciences, 116, 1819-1825.

Creswell, J. W. (2007). Qualitative inquiry \& research design: Choosing among five approaches $\left(2^{\text {nd }}\right.$ ed.). Thousand Oaks, California, the United States of America: Sage Publications, Inc.

Creswell, J. W., \& Poth, C. N. (2018). Qualitative inquiry \& research design: Choosing among five approaches ( $4^{\text {th }}$ ed.). Thousand Oaks, California, the United States of America: Sage Publications, Inc.

Dafouz, E. \& Camacho-Miñano, M. M. (2016). Exploring the impact of English-medium instruction on university student academic achievement: The case of accounting. English for Specific Purposes, 44, 57-67. http://dx.doi.org/10.1016/j.esp.2016.06.001

Du, X., \& Jackson, J. (2018). From EFL to EMI: The evolving English learning motivation of Mainland Chinese students in a Hong Kong university. System, 76, 158-169. https://doi.org/10.1016/j.system.2018.05.011

Goodman, B. A. (2019). Text, talk, and stance: Nigerian and Ukrainian student presentations in English-medium classes at a Ukrainian university. Linguistics and Education, 53, 1-8. https://doi.org/10.1016/j.linged.2019.100757

Hengsadeekul, C., Koul, R., \& Kaewkuekool, S. (2014). Motivational orientation and preference for English-medium programs in Thailand. International Journal of Educational Research, 66, 35-44. https://doi.org/10.1016/j.ijer.2014.02.001

Huang, D.-F. (2015). Exploring and assessing effectiveness of English medium instruction courses: The students' perspectives. Procedia - Social and Behavioral Sciences, 173, $71-$ 78.

Lincoln, Y. S. \& Guba, E. G. (1985). Naturalistic inquiry. Newbury Park, CA: Sage Publications. Macaro, E. \& Akincioglu, M. (2017). Turkish university students' perceptions about English medium instruction: Exploring year group, gender and university type as variables. 
Journal of Multilingual and Multicultural Development, 38(3), 1-15. http://dx.doi.org/10.1080/01434632.2017.1367398

Margic, B. D. \& Vodopija-Krstanovic, I. (2018). Language development for English-medium instruction: Teachers' perceptions, reflections and learning. Journal of English for Academic Purposes, 35, 31-41. https://doi.org/10.1016/j.jeap.2018.06.005

Mengxia Kong, M., \& Wei, R. (2019). EFL learners' attitudes toward English-medium instruction in China: The influence of sociobiographical variables. Linguistics and Education, 52, 44-51. https://doi.org/10.1016/j.linged.2019.03.005

Pritasari, A., Reinaldo, H., \& Watson, C. W. (2019). English-medium instruction in Asian business schools: A case study. Journal of Multilingual and Multicultural Development, 4O(1), 1-13. https://doi.org/10.1080/01434632.2018.1458855

Querol-Julián, M., \& Camiciottoli, B. C. (2019). The impact of online technologies and English medium instruction on university lectures in international learning contexts: $A$ systematic review. ESP Today, 7(1), 2-23. https://doi.org/10.18485/esptoday.2019.7.1.1

Rivero-Menéndez, M. J., Urquía-Grande, E., López-Sánchez, P., \& Camacho-Minano, M. M. (2018). Motivation and learning strategies in accounting: Are there differences in English as a medium of instruction (EMI) versus non-EMI students? Revista de Contabilidad Spanish Accounting Review, 21(2), 128-139. https://doi.org/10.1016/j.rcsar.2017.04.002

Suliman, W. A., \& Tadros, A. (2011). Nursing students coping with English as a foreign language medium of instruction. Nurse Education Today, 31, 402-407. https://doi.org/10.1016/j.nedt.2010.07.014

Tatzl, D. (2011). English-medium masters' programmes at an Austrian university of applied sciences: Attitudes, experiences and challenges. Journal of English for Academic Purposes, 10, 252-270.

Thomas, N. (2019). English language and medium of instruction in basic education in low- and middle-income countries: A British Council perspective, John Simpson. British Council Position Paper on EMI. British Council, London (2017). System, 82, 182-184. https://doi.org/10.1016/j.system.2019.02.005

Tuomainen, S. (2018). Supporting non- native university lecturers with EMI. Journal of Applied Research in Higher Education, 10(3), 230-242. https://doi.org/10.1108/JARHE-03-20170022

Wang, Y., Yu, S., \& Shao, Y. (2018). The experiences of Chinese mainland students with English-medium instruction in a Macau University. Educational Studies, 44(3), 357-360. http://dx.doi.org/10.1080/03055698.2017.1373635

Wanphet, P. \& Tantawy, N. (2018). Effectiveness of the policy of English as a medium instruction: Perspectives and outcomes from the instructors and students of university science courses at a university in the UAE. Educational Research for Policy and Practice, $17,145-172$.

Yang, M., O'Sullivan, P. S., Irby, D. M., Chen, Z., Lin, C., \& Lin, C. (2019). Challenges and adaptations in implementing an English-medium medical program: A case study in China. BMC Medical Education, 19(15), 1-8. https://doi.org/10.1186/s12909-018-1452-3

Yıldırım, A., Şimsek, H. (2013). Sosyal bilimlerde nitel araştırma yöntemleri ( $9^{\text {th }}$

Yin, R. K. (2009). Case study research: Design and methods ( $4^{\text {th }}$ ed.). The United States of America: SAGE Publications, Inc.

Zhang, H. (2017). What makes an effective English-medium course in China? Experiences and perspectives of international undergraduates. RELC Journal, 49(4), 1-16. 